Article

\title{
Research of the Critical Capitalization Rate in Building Damage Appraisal
}

\author{
Serena Artese (D), Manuela De Ruggiero *, Francesca Salvo and Raffaele Zinno (D)
}

Citation: Artese, S.; De Ruggiero, M.; Salvo, F.; Zinno, R. Research of the Critical Capitalization Rate in Building Damage Appraisal. Sustainability 2022, 14, 486. https:/ / doi.org/10.3390/su14010486

Academic Editor: Nicholas Chileshe

Received: 30 November 2021

Accepted: 29 December 2021

Published: 3 January 2022

Publisher's Note: MDPI stays neutral with regard to jurisdictional claims in published maps and institutional affiliations.

Copyright: (c) 2022 by the authors. Licensee MDPI, Basel, Switzerland. This article is an open access article distributed under the terms and conditions of the Creative Commons Attribution (CC BY) license (https:// creativecommons.org/licenses/by/ $4.0 /)$.

\author{
Department of Environmental Engineering, University of Calabria, 87036 Rende, Italy; \\ serena.artese@unical.it (S.A.); francesca.salvo@unical.it (F.S.); raffaele.zinno@unical.it (R.Z.) \\ * Correspondence: manueladeruggiero@gmail.com; Tel.: +39-348-156-9226
}

\begin{abstract}
From the perspective of building health monitoring and property management, this research proposes some parametric measures of the capitalization rate, in order to define a range of significant values to be used in a cash flow analysis intended for monetary evaluation in partial building damage assessment. If criteria and methods for appraising partial damage to buildings are widely shared in the scientific and professional communities, the identification of the most appropriate capitalization rate is rather more controversial, and certainly more complex. The proposed approach borrows the logical principles of cash flow analysis based on the yield capitalization approach, considering both recovery costs and loss of incomes when building partial damage occurs. The procedure is a differential valuation that considers a situation before and a situation after the damage, basing on the cost approach and the income approach. In particular, two distinct conditions are considered: the case of recovery interventions and that of improvement.
\end{abstract}

Keywords: building partial damage; capitalization rate; structural health monitoring

\section{Introduction}

During its lifecycle, civil infrastructure should always meet the safety requirements for which it has been designed. Civil engineering buildings, however, often degrade over time both due to the aging of materials and to natural or anthropogenic phenomena that can affect them.

In recent decades, monitoring building health has become important in structure management and studies, thanks to the use of increasingly advanced technologies involving sensors and their networks, the acquisition and communication of data, and their processing and management [1]. Structural health monitoring (SHM) refers to the process of implementing a damage detection and characterization strategy for engineering structures. In this sense, damage is defined as a change in the material and/or geometric properties of a structural system, including changes in the boundary conditions and connectivity of the system, which negatively affect the building performance [2].

It is clear that monitoring the structural health of a building or infrastructure has multiple values, indisputably linked to the need to prevent harm to people, but also to the opportunity to protect the economic value of real estate resources. The early identification of any damage to structures allows the damage environment to be contained, avoiding the total loss of value, in compliance with resilience and economic sustainability.

The assessment of the economic impact of damage relies on a transversal and integrated approach between structural engineering, which allows the identification and characterization of physical damage, and appraisal science, whose activity is the corresponding monetary quantification.

From a methodological point of view, the criteria and methods for appraising partial damage to buildings are related in the literature, albeit in an extremely simplified way, to the criterion of the reconstruction cost (or rather to the restoration cost), once the physical 
damage and remedies are completely defined. In more precise terms, however, it is a double evaluation that requires an ex ante estimate and an ex post one, requiring financial analysis tools in order to be able to make the comparison.

This circumstance involves a more specific, more controversial, and certainly more complex issue, referable to the identification of the appropriate capitalization rate to be used in the analysis of cash flows.

This paper intends to provide some parametric measures of the critical capitalization rate, in order to contain the rate range variability within the limits of appraising significance.

Starting from the presentation of the general concepts about damage and its classification (Section 2), the main methodological issues regarding the assessment of partial damage to buildings are addressed (Section 3), and the topic of the critical capitalization rate is discussed in more detail, proposing the parametric measurement both in the case of recovery interventions (Section 4) and in that of improvement (Section 5), which is briefly discussed in the conclusions (Section 6).

\section{Damage: Definition and Classification}

The term "damage" has numerous definitions in the literature, each related to a problematic area, but all converging towards a common interpretation: damage is any economic prejudice that results in a real decrease in assets for a specific subject and that occurs as a consequence of any human-provoked or fortuitous event [3].

Based on this interpretation, the constituent elements of damage are as follows:

- An event attributable to human conduct or accidental events;

- A change for the worse, or harm, in the economic consistency of a certain asset;

- A person who owns the asset who suffers this damage.

It has to be underlined that the mere occurrence of the material element of the unlawful fact is not sufficient to impose the obligation to pay compensation. The unlawful act must always occur due to non-observance of specific rules of conduct (compensable damage). When these conditions are not met, the obligation to compensate for the damage cannot be attributed to any person (non-compensable damage).

There are multiple types of damage and valuation circumstances, meaning that it is necessary to specify classifications and definitions, the nature of the events, and the corresponding effects related to the characteristics of the assets and of the affected people.

In any case, the physical components of the asset are the object of the damage that has suffered the harmful event. The damage, in fact, consists in a worsening of the quantitative and/or qualitative attributes possessed by the property and in a consequent reduction in or loss of their initial economic consistency.

One of the paradigms of the different forms that damage can take may be determined by its classification methods [4].

The first distinction separates private damage from public damage, regardless of the legal nature of the asset that suffers the damage [5]. It is private or public according to the perspective analysis from which the harmful effects deriving from the event are observed. Both for a private asset and a public one, the damage can consist in the injury of a private or subjective interest (private damage) and/or in the injury of a public or super-individual interest (public damage).

When the affected asset is a private one, private damage is revealed in the worsening of the economic and productive characteristics of the property and in the consequent impairment of the right of the person who owns it. Public damage, on the other hand, is attributable to the disadvantage suffered by the community as a result of the damage to a super-individual interest.

When the event damages a public asset in the strict sense (pure public asset), or a private property that carries out both private and public functions (mixed asset), the private damage concerns the loss of property and/or non-property types suffered by the individual member of the community or, if the object of the damage is a mixed asset, by the individual 
to whom the ownership of the asset is legally attributed. Public damage, on the other hand, consists in the prejudice that the event causes to the community as a whole.

A further classification is intended to distinguish physical damage from monetary damage. Physical damage expresses the modification suffered by the asset affected by the event in the form of quantitative and/or qualitative attributes [6]. There are different forms of physical (or material) damage: in particular, total damage and partial damage. Total damage is caused if a thing is destroyed or lost, or if a repair is impossible. In this case, material damage is the compensation of the damaged thing. Partial damage, on the other hand, is caused if the damaged thing can be repaired and resume its original function.

Monetary damage translates these modifications into monetary terms, reducing the physical aspects of the damage to a common numerary.

As a rule, the definition of the physical damage precedes the quantification of the monetary damage, which is obtained by applying the unit prices of the compromised resources to the modality of the physical damage, expressed in terms of variation in the quantitative and qualitative consistency of the asset. The prices adopted must reflect the actual degree of utility of the resources for the owner or community to whom the quantification of the monetary damage refers.

Monetary damage is configured as economic damage when the modification concerns the stock of capital and the flow of income [7]. Economic damage is, at the same time, loss of value concerning a certain stock of capital (damnum emergens-emerging damage) and an alteration, or interruption, of a series of future income (lucrum cessan-loss of profit) [8]. The first type is attributable to the amount of expenses necessary to eliminate or contain the harmful effect; the second, on the other hand, concerns the decrease in utility due to the worsening of the qualitative/quantitative characteristics of the affected property. The cost of restoring the damaged asset represents material damage, while the financial damage equals the present value of future lost income.

In general terms, it is still possible to distinguish tangible damage from intangible damage [9]. In principle, the damage manifests itself as the following:

- Change in inputs (increase in costs) and/or in outputs (decrease in revenues) relating to the affected economic activities. The damage therefore derives from the compromise of productive resources;

- Reduction in the degree of well-being in a broad sense. The damage derives from the alteration of non-productive resources.

Damage caused to productive resources, since it can be translated into monetary terms starting from the market prices of the damaged assets, is usually classified as tangible damage. On the other hand, damage that cannot be directly expressed in monetary terms is defined as intangible or extra-economic damage, given the non-commercial nature of the assets affected by the event (for example, properties with particular historical, architectural, cultural, artistic, or environmental values).

From a methodological perspective, damage assessment can be preventive (ex ante appraisal) or consumptive (ex post appraisal) [10]. In the first case, the assessment concerns the forecast of the extent of the damage that can be produced by a hypothetical event; in the second, the extent of the damage resulting from an event that actually occurred must be ascertained. Preventive damage is therefore defined as that assessed at a zero time in the temporal horizon within which the event is located. Instead, final damage is defined when the assessment is carried out at the final time in the temporal horizon. The appraisal of preventive damage is given by the comparison between a real previous situation and a hypothetical posterior situation, while that of the final damage is given by the comparison between a hypothetical previous situation and a real posterior situation.

In this paper, we focus on a specific type of material damage, namely, partial structural damage in buildings.

Any change introduced in the system itself that negatively affects its current and future performance compared to the initial state can be defined as structural damage of a system, assumed as not being damaged in the initial state [11]. The system changes concern 
materials, geometric properties, boundary conditions, and constraint configuration. The effects of the damage are accentuated when the system is subjected to operating loads that cause the structure to lose efficiency. The damage can progressively increase over time, such as in the case of corrosion or stress phenomena, and also lead to the collapse of the structure, or it can occur in short periods of time, as in the case of natural events such as earthquakes and landslides.

Structural damage is physical, but it can be accompanied by loss of income or capital, also leading to material damage. It can involve tangible resources but also intangible ones, when the damage occurs in buildings with particular historical, artistic, architectural, and cultural value. Damage to existing buildings, related to degradation or due to accidental events, can affect their functionality, usability, and existence.

The type of intervention on heritage buildings will be determined by the present situation and, in addition, by its cultural value. It ranges from simple maintenance and repair to deep restoration when it is intended to improve the performance and life of the building.

Assessment of structural damage may be necessary in many practical circumstances, such as in the case of legal disputes, but more generally, it is always appropriate when aiming to protect existing housing stock, which inevitably requires the assessment of recovery costs and related losses.

For this to be possible, material damage must be clearly identified and defined, even when it is not yet fully visible.

One method to evaluate the safety and duration of a structure during its useful life, to ensure its sustainability and functionality and to identify the type of intervention, is structural health monitoring [12].

\section{Structural Health Monitoring and Damage Detection}

Structural health monitoring (SHM), together with condition monitoring (CM), nondestructive evaluation (NDE), statistical process control (SPC), and damage prognosis (DP), through the most recent techniques of survey and data processing, allows the identification, evaluation, and monitoring, with ever-increasing clarity, of the structural characteristics and the level of damage of any building, and, therefore, the prediction of its trend over time [13].

The use of traditional and experimental sensor networks [14,15] and the processing of data obtained from them allow the identification of anomalies in the behavior of structures in operation, as well as the implementation of early warning systems. Monitoring systems can also be used to create a database of measurements detected during the entire life cycle of the structure.

In accordance with the aim of damage appraisal, it is important to identify and define the damage completely. Rytter proposed the following hierarchical structure [16]:

- Damage Detection: returns qualitative information on the possible presence of damage on the structure;

- Damage Location: returns information on the probable location of the damage;

- Damage Assessment: returns information on the extent and/or location of the damage;

- Prediction: returns information on structural safety such as the residual life of the structure.

\section{Monetary Damage Evaluation: Methodological Issues}

Monetary damage evaluation involves, in very general terms, the definition of a situation prior to the occurrence of the harmful event and the a posteriori identification of the physical effects produced by the event itself $[17,18]$, in compliance with the principles of uniformity defined by the International Valuation Standards [19].

If the damage is total, the amount of damage can be equated to the depreciated rebuilding cost. The economic criterion is that of the depreciated cost, considering the physical, technological, and economic obsolescence of the asset in the instant immediately 
prior to the occurrence of the harmful event. Monetary damage is derived through the cost approach.

If the damage is partial, the assessment is resolved, at least as a first approximation, in the determination of the cost of the interventions aimed at eliminating the effects of the event, i.e., at restoring the normal physical and functional conditions of the damaged property, possibly also considering the lack of related profitability.

It should be noted that, in the presence of partial damage of exceptional gravity, or when the effects of the damage do not end with the restoration but occur over more or less long time intervals, leading to a reduction in the economic duration of the property or an increase in maintenance costs, when appraising the damage, the economic degradation that occurs in the market for a restored building due to structural damage, with respect to a similar building in which interventions have never been necessary (criterion of the transformation value), has to be considered [20].

Conversely, an increase in the value of a building affected by a recovery intervention can also occur, which, as a result of the recovery action, can present a higher market value than it had before the harmful event.

Therefore, in general terms, the assessment of partial building damage involves a double assessment, which takes into account a situation prior to and a situation subsequent to the damage, both referring to the same moment.

As the first approximation, an elementary measure of partial damage is the cost of restoration when the return to the original situation is possible and economically advantageous (this latter circumstance requires the cost to be greater than or equal to the damage suffered).

In assessing the damage to properties, the temporal implication of the interventions requires the construction of a cash flow, calculated by the costs of the building interventions, their duration, changes in income flows, and discount rates.

One of the main difficulties related to this approach consists in the choice of the capitalization rate, which defines the relationship between the value of the capital and the sum of money that is obtained from it in a certain period [21].

Choosing the capitalization rate implies a very complex appraisal analysis because, if comparative data from the market are absent, it is linked to the need to take into consideration numerous factors and to know how to weight them correctly and objectively, also making sure that the results are demonstrable. The difficulty is more specifically related to the impossibility of defining an algorithmic link between income and value, a difficulty even more evident considering that even minimal percentage variations in the amount of the discount rate translate into much more significant alterations in terms of appraised values [22].

The choice of the capitalization rate can include a direct survey, based on the detection of prices and annuities indicated by the market, or an indirect approach, aimed at analyzing the circumstances that quantitatively affect its amount.

In the latter and more frequent condition, the problem of determining the rate is solved in the construction of mathematical models (of a deterministic type) based on the causative aspects, and on the relationships and economic links between the estimative quantities and the capitalization rate [23].

In the context of indirect methods, one of the first historically proposed procedures is the analogue method, based on which the valuation of the capitalization rate is carried out by processing the rates of return of alternative investments to that of real estate. Obviously, these are procedures of modest reliability, because they are determined by the "personality and subjectivity" of the valuer [24].

The appraisal theory also proposes the use of the so-called additive method, according to which the capitalization rate is obtained starting from a minimum risk rate, considering the additive contributions linked to the influences that certain circumstances determine. All possible factors that affect the average rate (and not the minimum risk rate) are evaluated, causing it to increase or decrease. The appraisal theory usually groups the influences on 
the basis of the different theories of interest proposed by the economic literature (interest as a risk reward; interest as a reward for abstinence; interest as a consequence of capital productivity; interest as a reward for the rarity of capital; interest as a reward for waiting; interest in relation to the duration of the investment; interest in relation to the exchange power of money) [25].

With regard to the indirect approach, it should be noted that, while being a precise analysis of the many factors that contribute to the formation of the capitalization rate, there are still all the limitations and approximations characteristic of empirical methods in terms of "subjectivity". The assignment of the percentages to be attributed to individual influences, while responding to precise indications, is directly conditioned by the ability and arbitrariness of the evaluator, and by the weight that they assign to the various causes affecting the discount rate.

Furthermore, it becomes rather difficult to justify and demonstrate the choice of a specific rate in place of another with objective tools, indispensable for guaranteeing transparency in the appraisal process; in addition, the verification of the results obtained requires the application of different methodologies, often onerous in the case of a single appraisal.

Finally, it must be pointed out that the additive method and the other methods based on a linear relationship violate the condition posed by the problem of income capitalization; this means that a certain increase or decrease in the rate with respect to a base rate induces non-proportional changes in the value.

Residual techniques are inspired by additive methods: the band of investment method, yield and change formulas, and the built-up capitalization rate method identify the capitalization rate on the basis of the technical, physical, and economic financial components of the considered real estate investment [26,27].

Finally, among the indirect procedures, it is necessary to include the financial models (Ellwood model, debt coverage ratio, after-tax cash flow approach): the capitalization rate is calculated by carrying out a financial analysis based on the principles of investment choices [28-31].

Alongside the aforementioned direct and indirect procedures, an interesting possibility consists in resorting to econometric models based on the direct survey of real estate data and on market evidence, in the same way as the direct approach, but characterized by an axiomatic-deductive approach in the interpretation of the causal relationships between the explanatory variables and the unknown one, similarly to what happens in indirect research. In particular, the appraisal of the capitalization rate is based on the construction of the econometric function of the rate, using the mathematical tools of differential calculus and Taylor series development, leading to the determination of the rate for any property similar to the sampled properties $[32,33]$.

With specific reference to the use of income techniques for estimating partial damage to buildings, it should be noted that there are positive and other negative contributions in the associated cash flows, with hypothetical circumstances occurring for which the estimated value is canceled; the capitalization rate at which this particular condition is met is called the "critical" rate $i_{c}$.

The critical capitalization rate must be evaluated a priori to identify the range within which it must be included $\left(0<i<i_{c}\right)$; values higher than the critical one, in fact, would produce negative and therefore unacceptable estimation results.

The present study aims to define some parametric measures of the discount rate to use when appraising building partial damage in ordinary circumstances. The search for parametric measures is developed through the yield capitalization approach, which aims to simulate a complete cycle of real estate investment, from the moment of initial purchase to that of final resale; the analysis of the cash flows of the damage includes the intermediate occurrences of the cycle. The cash flow analysis considers the economic and valuation conditions of the property damage and the temporal implications of building interventions through discount rates. For the economic conditions, the legal and factual conditions and 
the highest and best use (HBU) of the building are considered. For the discount rate, the mathematical conditions of existence and the significant economic measure are assumed.

\section{Appraisal of the Critical Capitalization Rate in Building Restoration Interventions}

We first examine the parametric discount rates in the case of restoration interventions aimed at bringing the property back to its original condition. Parametric discount rates are also proposed when the restoration intervention induces an economic surplus in the property, which is configured, for example, as the reconstitution of a new value.

The economic extent of the damage done to a building refers to the reduction in its market value with respect to the situation prior to the adverse event [18]. In partial damage, owing to the loss of one or more parts of a building or the entire building itself, with the exclusion of any recovery of materials and the value of the building land, the elementary damage is measured by the cost of the restoration, when the reconstitution of the original situation is possible and economically advantageous, i.e., in the condition that the cost is greater than or equal to the damage suffered [34].

The building restoration project aims to restore the initial situation of the property before the damage $[35,36]$.

In elementary conditions, the recovery intervention contrasts the physical deterioration of the damaged part or parts of the building. For the purposes of compensation for partial damage, the cost of recovery also includes the loss of income of the property within the period of the intervention, assuming an equal restoration of the initial profitability.

It should be considered that the recovery intervention can also generate a surplus in the new conditions compared to those current at the time of the damage.

The cost of restoration (damnum emergens and lucrum cessans) can be estimated in the cash flow through yield capitalization, considering recovery costs and loss of income.

The appraisal of the market value considers the series of revenues from the date of purchase to the time of final resale, meaning that the market value $V$ is the net present value of the cash flow of the entire real estate cycle:

$$
V=\sum_{t=0}^{n-1} \overline{R_{t}} \cdot(1+i)^{-t}+V_{n} \cdot(1+i)^{-n}
$$

where:

$\overline{R_{t}}$ is the average income of the property;

$V_{n}$ is the final resale value of the property;

$n$ is the duration of the investment;

$t$ is the generic time;

$i$ is the annual capitalization rate.

The partial damage assessment is a differential valuation that considers a situation before and after the damage, referring to the same date.

Recovery interventions can have different durations and require fractional payments (with deadlines of less than one year). Consequently, the present value of the cash flow of the property in the situation prior to the damage $V_{a}$ must refer to fractional periods such as

$$
V_{a}=\sum_{t=0}^{n \cdot k-1} \overline{R_{t}} \cdot\left(1+i_{k}\right)^{-t}+V_{n} \cdot\left(1+i_{k}\right)^{-n k}
$$

where:

$R_{t}$ is the periodical anticipated income;

$k$ is the frequency of installments in every year;

$i_{k}$ is the equivalent period rate.

The final resale value $V_{n}$ can be expressed with respect to the initial market value (revalued or depreciated) considering a rate per year $d$ and for the $\mathrm{n}$ duration of the investment period: 


$$
V_{n}=V_{a} \cdot\left(1+n \cdot \frac{d}{k}\right)
$$

The market value of the property in the situation prior to the occurrence of the damage can therefore be expressed considering (2) and (3) as

$$
V_{a}=\sum_{t=0}^{n \cdot k-1} R_{t} \cdot\left(1+i_{k}\right)^{-t}+V_{a} \cdot\left(1+n \cdot \frac{d}{k}\right) \cdot\left(1+i_{k}\right)^{-n k}
$$

The market value of the property in the situation following the damage can be estimated on the same cash flow, considering, in addition, all the costs necessary to restore the initial condition (i.e., the same profitability):

$$
V_{p}=-\sum_{t=0}^{m \cdot k} C_{t} \cdot\left(1+i_{k}\right)^{-t}+\sum_{t=m \cdot k+1}^{n \cdot k-1} R_{t} \cdot\left(1+i_{k}\right)^{-t}+V_{a} \cdot\left(1+n \cdot \frac{d}{k}\right) \cdot\left(1+i_{k}\right)^{-n k}
$$

where:

$C_{t}$ is the periodical recovery cost;

$m$ is the duration of recovery.

In the cash flow of the market value of the property in the post-event situation, the costs precede the revenues and, if the sum of the items is positive, there is a positive critical capitalization rate $i_{k}$ for which the market value $\left(V_{p}\right)$ is zero [22]: for rates above the critical rate, the market value is negative. In economic terms, the critical rate is the internal rate of return of the owner's recovery investment in order to restore the initial profitability of the existing property.

Partial damage $D$ caused to a property is therefore equal to the difference between the market value in the previous situation and that relating to the subsequent situation, referring to the same date, that is, substituting (4) and (5):

$$
D=V_{a}-V_{p}=\sum_{t=0}^{m \cdot k} C_{t} \cdot\left(1+i_{k}\right)^{-t}+\sum_{t=0}^{m \cdot k} R_{t} \cdot\left(1+i_{k}\right)^{-t}
$$

The damage is therefore equal to the present value of the cash flow obtained by subtracting the net present value of the situation after the respective maturities from the cash flow of the present value in the initial situation [22].

The damage function decreases and is not determined by the final market value of the property. At the same rate, the amount of damage remains constant because it does not depend on the duration of the investment period, but exclusively on the sum of costs and lost earnings.

The damage function intercepts the property market value functions, both the function referring to the previous conditions and that based on the subsequent conditions: the first in correspondence with the critical capitalization rate $\left(V_{a}=D\right)$, and the second in correspondence with a limit rate, for which the market value in the subsequent situation is equal to the damage itself $\left(V_{p}=D\right)$ (Figure 1). In the latter circumstance, for discount rates above the limit rate, the partial damage would exceed the market value of the property in the subsequent situation, meaning it would be inconsistent with the extent of the damage itself.

The search for the critical capitalization rate of the damage can be carried out by setting the equality between the damage function $D$ and the market value function $V_{p}$ :

$$
D=V_{p}
$$

obtaining

$$
2 \cdot \sum_{t=0}^{m \cdot k} C_{t} \cdot\left(1+s_{k}\right)^{-t}+\sum_{t=0}^{m \cdot k} \overline{R_{t}} \cdot\left(1+s_{k}\right)^{-t}-\sum_{t=m \cdot k+1}^{n \cdot k-1} R_{t} \cdot\left(1+s_{k}\right)^{-t}-V_{a} \cdot\left(1+n \cdot \frac{d}{k}\right) \cdot\left(1+s_{k}\right)^{-n k}=0
$$




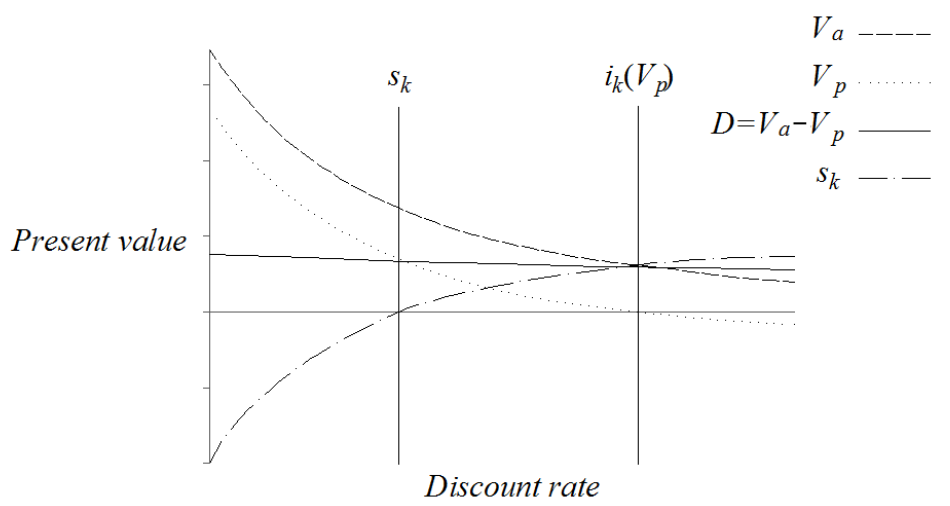

Figure 1. Market value/capitalization rate.

Equation (8) is a polynomial function that corresponds to a fictitious cash flow which, when resolved, leads to the determination of the critical discount rate $s_{k}$, meaning that in the appraisal of the partial damage, the choice of the discount rate must be included in the range $] 0 ; s_{k}[$.

The recovery intervention to counter the physical deterioration of a part or parts of the building or the building itself can generate an excess in the new conditions compared to those existing at the time of the damage, with an increase in income in the subsequent availability period upon recovery and/or with an increase in the final market value.

In the condition of capital gain and final market value $V_{p}^{\prime}$, the situation after the damage is equal to

$$
V_{p}^{\prime}=-\sum_{t=0}^{m \cdot k} C_{t} \cdot\left(1+i_{k}\right)^{-t}+\sum_{t=m \cdot k+1}^{n \cdot k-1} R_{t}^{\prime} \cdot\left(1+i_{k}\right)^{-t}+V_{n}^{\prime} \cdot\left(1+i_{k}\right)^{-n k},
$$

where:

$R_{t}^{\prime}$ is the increased periodic income $\left(R_{t}^{\prime}>R_{t}\right)_{t}$

$V_{n}^{\prime}$ is the property final market value $\left(V^{\prime}{ }_{n}>V_{n}\right)$.

Costs precede revenues in the cash flow of the property market value in the final situation, and if the sum of the items is positive, there is a positive critical capitalization rate $i_{k}\left(V_{p}^{\prime}\right)$ for which the value in the following situation is zero [22]: for rates above the critical rate, the market value is negative.

If the market value in the situation after the damage is higher than in the previous situation $\left(V_{p}^{\prime}>V_{a}\right)$, a benefit is generated despite the damage. This benefit can be calculated as the gross or net of the damage.

The cash flow of the gross benefit considers the increase in income for the residual time horizon and the revaluation of the final value of the property as the difference between the cash flow of the market value with the excess and the market value of the property in the situation following the damage in the case of recovery $\left(V_{p}^{\prime}-V_{p}\right)$.

The net benefit obtained by subtracting the amount of damage from the gross benefit is interesting. The cash flow of the net benefit $B$ is presented as the difference between the cash flow of the market value of the surplus and the cash flow of the market value in the initial situation as follows, according to (9) and (4):

$$
B=V_{p}^{\prime}-V_{a}=\sum_{t=m \cdot k+1}^{n \cdot k-1}\left(R^{\prime}{ }_{t}-R_{t}\right) \cdot\left(1+i_{k}\right)^{-t}+\left(V^{\prime}{ }_{n}-V_{n}\right) \cdot\left(1+i_{k}\right)^{-n k}-D .
$$

The function of the net benefit with the profitability surplus decreases and is determined by the final market values of the property. In the cash flow of the net benefit, the damage suffered with a negative sign precedes the revenues, and since the sum of the revenues is greater than the damage, there is a positive limit discount rate $i_{k}(B)$ for which the 
net benefit is zero. Consequently, for rates above the limit rate, the net benefit is negative, that is, paradoxically, configured as damage.

To calculate the net benefit, it is necessary to know the difference between the final market values of the property, considered in the same market segment.

For evaluation purposes, the final resale value in the post-damage situation can be expressed with respect to the initial market value with an annual rate of change $d^{\prime}$, which includes any capital gain, and for the duration of the availability period [37]. According to (3), it is

$$
V_{n}^{\prime}=V_{a} \cdot\left(1+n \cdot \frac{d^{\prime}}{k}\right)
$$

meaning that

$$
V_{n}^{\prime}-V_{n}=V_{a} \cdot \frac{n}{k}\left(d^{\prime}-d\right)
$$

In the net benefit, therefore, the difference between the final market values of the property is equal to the market value in the original situation multiplied by a factor that takes into account the projection period and any capital gain.

Finally, the net benefit can be defined considering (10) and (12):

$$
B=V_{p}^{\prime}-V_{a}=\sum_{t=m \cdot k+1}^{n \cdot k-1}\left(R_{t}^{\prime}-R_{t}\right) \cdot\left(1+i_{k}\right)^{-t}+V_{a} \cdot \frac{n}{k}\left(d^{\prime}-d\right) \cdot\left(1+i_{k}\right)^{-n k}-D .
$$

\section{Appraisal of the Critical Capitalization Rate in Building Improvement Interventions}

In conjunction with the damage, sometimes the owners can intervene with replacement and integration operations of parts of the building or the entire building itself affected by the damage, adding them to the planned interventions. In residential buildings, these interventions are related to the modernizations and adjustments imposed by the legislation; in instrumental buildings, these interventions are related to renovations, reconversions, etc. In these circumstances, the damage must be separated from the investments. The transformation work is intended to tackle physical degradation and functional obsolescence of the building and reallocate the property to its highest and best use, making an investment choice [38].

In general, in the case of transformation interventions (renovation, restoration, etc.), the market value of the property to be transformed is equal to the net present value of the cash flow which includes the transformation costs for the entire duration of the intervention, the subsequent income, and the value of the transformed property [39].

According to yield capitalization, the transformation value $V^{*}$ of the property is equal to

$$
V^{*}=-\sum_{t=0}^{m^{*} \cdot k} C^{*}{ }_{t} \cdot\left(1+i^{*}{ }_{k}\right)^{-t}+\sum_{t=m \cdot k+1}^{n \cdot k-1} R^{*} \cdot\left(1+i_{k}^{*}\right)^{-t}+V_{n}^{*} \cdot\left(1+i_{k}^{*}\right)^{-n k},
$$

where:

$C^{*}{ }_{t}$ represents the transformation fractional costs;

$R^{*}{ }_{t}$ represents the property fractional incomes;

$m^{*}$ is the duration of the transformation intervention $\left(m^{*}>m\right)$;

$n$ is the horizon time;

$k$ is the annual frequency;

$t$ is the generic time;

$V^{*}{ }_{n}$ is the value of the transformed property (property value after improvement);

$i^{*}{ }_{k}$ is the periodical capitalization rate.

In the cash flow of the market value of the property to be transformed, costs precede revenues, and if the sum of the items is positive, there is a positive critical capitalization rate $i_{k}$ for which the transformation value $\left(V^{*}\right)$ is zero; for rates greater than the critical rate, the transformation value is negative. In economic terms, the rate represents the internal 
rate of return of the property investment on which to intervene with the transformation (Figure 2) $[40,41]$.

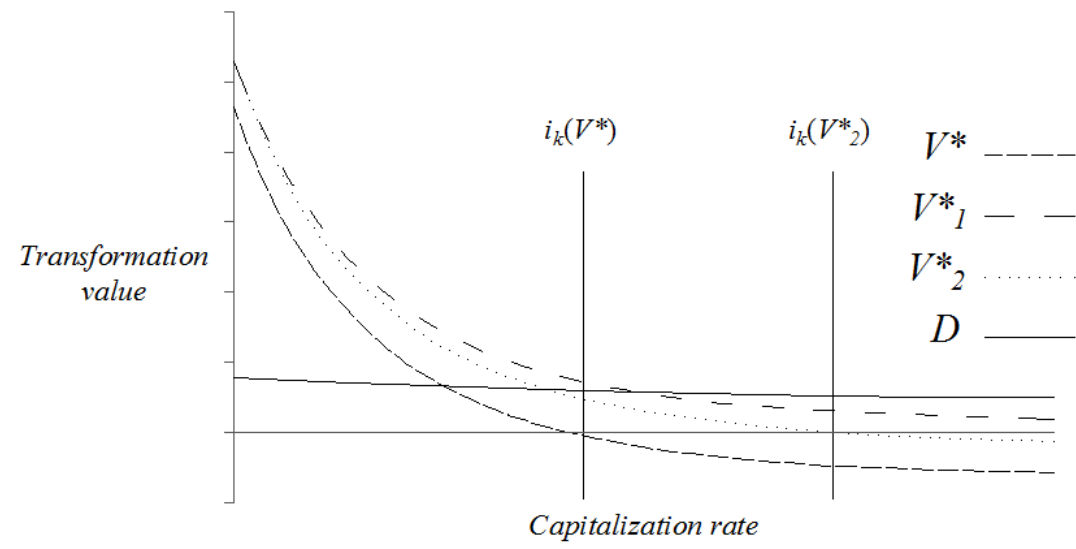

Figure 2. Transformation value/capitalization rate.

For the purposes of the valuation, the final market value of the transformed property cannot be expressed using the same rate, as the transformed property and the one to be transformed are most likely related to different market segments [22,36].

Consequently, the intermediate value of the property referring to the date in which the transformation is complete (typically at the moment $m^{*}$ at the end of the works) can be used as a methodological intermediary. The intermediate value $V_{m}{ }^{*}$ is defined as the present value of the cash flow of the remaining projection period $\left(n-m^{*}\right)$ and can be calculated as follows:

$$
V_{m^{*}}=\sum_{t=m^{*} \cdot k+1}^{n \cdot k-1} R^{*} \cdot\left(1+i_{k}^{*}\right)^{-\left(t-m^{*} \cdot k\right)}+V_{n}^{*} \cdot\left(1+i_{k}^{*}\right)^{-\left(n-m^{*}\right) \cdot k}
$$

The final resale value can be expressed with reference to the initial market value, revalued or depreciated using a rate $d^{*}$ referring to the market segment of the transformed property for the duration of the projection period:

$$
V_{n}^{*}=V_{m^{*}} \cdot\left[1+\left(n-m^{*}\right) \cdot d^{*}\right] .
$$

Substituting the resale value of Formula (16) in (15):

$$
V_{m^{*}}=\frac{\sum_{t=m^{*} \cdot k+1}^{n \cdot k-1} R^{*} \cdot\left(1+i^{*}\right)^{-\left(t-m^{*} \cdot k\right)}}{1-\left[1+\left(n-m^{*}\right) \cdot d^{*}\right] \cdot\left(1+i^{*}\right)^{-\left(n-m^{*}\right) \cdot k}} .
$$

Thus, the transformation value can be reformulated as a function of the intermediate value:

$$
V^{*}=-\sum_{t=0}^{m^{*} \cdot k} C^{*} \cdot\left(1+i_{k}^{*}\right)^{-t}+V_{m^{*}} \cdot\left(1+i_{k}^{*}\right)^{m^{*} \cdot k}
$$

in which, by substituting the final resale value $V_{m}{ }^{*}$, we obtain

$$
V^{*}=-\sum_{t=0}^{m^{*} \cdot k} C^{*}{ }_{t} \cdot\left(1+i^{*}{ }_{k}\right)^{-t}+\frac{\sum_{t=m^{*} \cdot k+1}^{n \cdot k-1} R^{*}{ }_{t} \cdot\left(1+i_{k}^{*}\right)^{-\left(t-m^{*} \cdot k\right)}}{1-\left[1+\left(n-m^{*}\right) \cdot d^{*}\right] \cdot\left(1+i^{*}{ }_{k}\right)^{-\left(n-m^{*}\right) \cdot k}} \cdot\left(1+i^{*}{ }_{k}\right)^{m^{*} \cdot k}
$$

In the case of transformation interventions of the damaged property, carried out in place of the recovery intervention, the market value of the property in the conditions following the damage can be carried out in two distinct ways: in the first case, considering the indemnity as anticipated by third parties in a lump sum and reinvested in the transforma- 
tion for an amount equal to the cost of recovery; in the second way, considering the damage to the owner distributed over the different deadlines. In both ways, the transformation value of the property is assessed by considering the other conditions relating to planning and management by the property or the company [42].

The net present values of the cash flows of the first and second modes lead to different results, except that in the second mode, the search for the critical rate can be facilitated by the lower position of the net present value curve.

\section{Conclusions}

The protection of real estate assets requires actions based on ad hoc tools intended to preserve the cultural, social, and economic value of the properties, from the perspective of people's well-being and safety.

This means implementing synergistic and multidisciplinary actions which, in identifying critical elements and potential for building transformations, can be achieved when economic sustainability is considered.

The preliminary identification of partial damage to buildings, which can be effectively conducted with structural health monitoring (SHM), allows the acquisition of information and data and the definition of working methods useful for determining the restoration interventions of any partial damage detected in buildings, and consequently quantifying the damage economically.

The assessment of the financial damage is based on a double appraisal, referring to the conditions before and after the damage, recalling the need to build a cash flow that includes the analysis of the restoration costs, the lost income, the respective durations, and, obviously, capitalization rates.

As discussed thus far, the main problem of the assessment is the determination of the most appropriate capitalization rate to be used in the financial analysis of the damage, given the fact that this value produces significant levels of variability in the results achieved.

In particular, this work intended to provide some parametric measures of the capitalization rate, in order to be able to define the range of variability by identifying the critical capitalization rate, that is, the value that effectively defines the economic convenience to restore the damage.

In particular, two distinct conditions were analyzed. The first refers to interventions purely aimed at restoring the damage. Under these conditions, costs precede revenues, meaning there is a critical capitalization rate $i_{k}\left(V_{p}\right)$ at which the market value is zero, or the market value of the property in the subsequent situation is equivalent to the damage itself; it follows that, in estimating the partial damage, this value cannot be exceeded, and the discount rate must fall within a range between zero and the critical rate itself, both excluded. The second situation refers to the case in which the restoration intervention, although aimed at containing the deterioration of the part or parts of the building, generates a surplus in the value of the transformed property compared to what it had before the occurrence of the harmful event. In essence, an economic benefit is realized as the net of the damage. Analyzing the corresponding cash flow, in this case, it is possible to identify a critical capitalization rate at which the market value of the transformed property is zero since, in this case, it is also possible to define an interval of variability of the rate.

These analyses can be further detailed, introducing other or different assumptions, but which, thanks to their parametric nature, prelude the implementation of automatic damage estimation procedures set up in a "phygital" environment [43], in which physical objects (physics) are connected and interfaced with digital information systems (sensor systems, building information modeling, neural networks, artificial intelligence, etc.), with a view to efficient and integrated management of real estate assets.

Author Contributions: Conceptualization, R.Z. and M.D.R.; methodology, R.Z., M.D.R. and F.S.; software, S.A. and M.D.R.; validation, R.Z. and F.S.; formal analysis, R.Z., F.S. and M.D.R.; investigation, R.Z. and M.D.R.; resources, F.S. and R.Z.; data curation, M.D.R. and S.A.; writing-original draft preparation, M.D.R. and S.A.; writing - review and editing, R.Z. and F.S.; visualization, S.A. and 
M.D.R.; supervision, R.Z.; project administration, R.Z.; funding acquisition, R.Z. and F.S. All authors have read and agreed to the published version of the manuscript.

Funding: This research received funding by the S3HM project (Savuto Smart Structural Health Monitoring), POR Calabria FESR-FSE 2014-2020-Asse I-Obiettivo specifico 1.3—Action 1.3.2Living Lab.

Institutional Review Board Statement: Not applicable.

Informed Consent Statement: Not applicable.

Data Availability Statement: This study did not report any data.

Conflicts of Interest: The authors declare no conflict of interest.

\section{References}

1. Zinno, R.; Artese, S.; Clausi, G.; Magarò, F.; Meduri, S.; Miceli, A.; Venneri, A. Structural health monitoring (SHM). In The Internet of Things for Smart Urban Ecosystems; Springer: Berlin/Heidelberg, Germany, 2019; pp. 225-249.

2. Zinno, R.; Artese, S. Innovative methods and materials in structural health monitoring of civil infrastructures. Appl. Sci. 2021, 11, 1140. [CrossRef]

3. Medici, G. Principi di Estimo; Edizioni Agricole: Bologna, Italy, 1998.

4. Moncelli, M. La Stima dei Danni al Patrimonio Immobiliare; Maggioli Editore: Santarcangelo di Romagna, Italy, 2016 ; Volume 215.

5. Geuss, R. Beni Pubblici Beni Privati. Origine e Significato di UNA Distinzione; Donzelli Editore: Rome, Italy, 2005.

6. Del Giudice, V.; Salvo, F. Principi e metodi di valutazione dei danni da esondazioni fluviali; Centro Editoriale e Librario Università della Calabria: Rende, Italy, 2006.

7. Forte, F.; Del Giudice, V.; De Paola, P.; Del Giudice, F.P. Cultural heritage and seismic disasters: Assessment methods and damage types. In Appraisal and Valuation; Springer: Cham, Switzerland, 2021; pp. 163-175.

8. Jorge, A.; Salazar-Carrillo, J. Lucrum cessans, damnum emergens and the market place. J. Forensic Econ. 1990, 4, 117-118. [CrossRef]

9. Harder, M.; Burford, G. Measuring Intangible Values: Rethinking How to Evaluate Socially Beneficial Actions; Routledge: London, UK, 2018.

10. Simonotti, M. Metodi di Stima Immobiliare. Applicazione Degli Standard Internazionali; Dario Flaccovio: Palermo, Italy, 2006.

11. Brownjohn, J.M. Structural health monitoring of civil infrastructure. Philos. Trans. R. Soc. A Math. Phys. Eng. Sci. 2007, 365, 589-622. [CrossRef] [PubMed]

12. Gopinath, V.K.; Ramadoss, R. Review on structural health monitoring for restoration of heritage buildings. Mater. Today Proc. 2021, 43, 1534-1538. [CrossRef]

13. Huston, D. Structural Sensing, Health Monitoring, and Performance Evaluation; CRC Press: Boca Raton, FL, USA, 2010.

14. Artese, S.; Zinno, R. TLS for dynamic measurement of the elastic line of bridges. Appl. Sci. 2020, 10, 1182. [CrossRef]

15. Artese, S.; Achilli, V.; Zinno, R. Monitoring of bridges by a laser pointer: Dynamic measurement of support rotations and elastic line displacements: Methodology and first test. Sensors 2018, 18, 338. [CrossRef] [PubMed]

16. Rytter, A. Vibration based inspection of civil engineering structures. Ph.D. Dissertation, Department of Building Technology and Structural Engineering, Aalborg University, Aalborg, Denmark, 1993.

17. Bell, R. The impact of detrimental conditions on property values. Apprais. J. 1998, 66, 380.

18. Bell, R.; Anderson, O.C.; Sanders, M.V. Real Estate Damages; Appraisal Institute: Chicago, IL, USA, 2016.

19. IVSC. International Valuation Standards; International Valuation Standards Council: London, UK, 2017.

20. Simonotti, M. Valutazione Immobiliare Standard; Stimatrix: Mantova, Italy, 2011.

21. Ciuna, M.; De Ruggiero, M.; Salvo, F.; Simonotti, M. Automatic research of the capitalization rate for the residential automated valuation: An experimental study in Cosenza (Italy). In Advances in Automated Valuation Modeling; D'Amato, M., Kauko, T., Eds.; Springer International Publishing: Berlin/Heidelberg, Germany, 2017; pp. 361-380.

22. Simonotti, M. Ricerca del saggio di capitalizzazione nel mercato immobiliare. Aestimum 2011, 59, 171-180.

23. Sivitanides, P.; Southard, J.; Torto, R.G.; Wheaton, W.C. The determinants of appraisal-based capitalization rates. Real Estate Financ. 2001, 18, 27-38.

24. Brizi, A. Lezioni di Metodo Dell'estimo Agrario; Facoltà di Agraria dell' Universita degli Studi di Napoli: Napoli, Italy, 1935.

25. Larriva, M.; Linneman, P. The determinants of capitalization rates: Evidence from the US real estate markets. J. Prop. Invest. Financ. 2021; ahead-of-print. [CrossRef]

26. Martin, J.H.; Sussman, M.W. The twelve Rs: An overview of capitalization rate derivation. Apprais. J. 1997, 65, 149.

27. Del Giudice, V.; Passeri, A.; De Paola, P.; Torrieri, F. Estimation of risk-return for real estate investments by applying Ellwood's model and real options analysis: An application to the residential real estate market of Naples. Appl. Mech. Mater. 2014, 651, 1570-1575. [CrossRef] 
28. Morano, P.; Manganelli, B.; Tajani, F. Real Options for risk analysis in estimating the capitalization rate. In Proceedings of the International Conference on Business Administration, Marketing and Economics, Venice, Italy, 28-30 September 2013; Neck, R., Ed.; Volume 12, pp. 25-30.

29. Chaney, A.; Hoesli, M. Transaction-Based and Appraisal-Based Capitalization Rate Determinants. Int. Real Estate Rev. 2015, 18, $1-43$.

30. Lennhoff, D.C. Direct capitalization: It might be simple but it isn't that easy. Apprais. J. 2011, 79, 66-74.

31. Lonergan, W. Pre and post tax discount rates and cash flows-a technical note. J. Appl. Res. Account. Financ. 2009, 4, 41-45.

32. Del Giudice, V. Stima econometrica del saggio di capitalizzazione. Genio Rural. 1995, 7, 18-28.

33. Sivitanidou, R.; Sivitanides, P. Office capitalization rates: Real estate and capital market influences. J. Real Estate Financ. Econ. 1999, 18, 297-322. [CrossRef]

34. Ciuna, M.; Pesce, S. Misura dell'incidenza della terra e dei miglioramenti fondiari. Estimo E Territ. 2006, 11, 12-20.

35. Di Ludovico, M.; Prota, A.; Moroni, C.; Manfredi, G.; Dolce, M. Reconstruction process of damaged residential buildings outside historical centres after the L'Aquila earthquake: Part I-"light damage" reconstruction. Bull. Earthq. Eng. 2017, 15, 667-692. [CrossRef]

36. Di Ludovico, M.; Prota, A.; Moroni, C.; Manfredi, G.; Dolce, M. Reconstruction process of damaged residential buildings outside historical centres after the L'Aquila earthquake: Part II—“'heavy damage” reconstruction. Bull. Earthq. Eng. 2017, 15, 693-729. [CrossRef]

37. Simonotti, M. Problemi di verifica del saggio di capitalizzazione. Estimo E Territ. 2009, Anno LXXII, 8-13.

38. Sirmans, C.F.; Jaffe, A.J. The Complete Real Estate Investment Handbook; Prentice Hall: New Jersey, NJ, USA, 1988.

39. Gaylon, G.E.; Michael, F.D.; Phillip, K.T. Investment Analysis for Real Estate Decision, 5th ed.; Dearborn Trade: La Crosse, WI, USA, 2003; p. 90.

40. Ciuna, M.; Pesce, S. L'applicazione dei saggi variabili nella stima analitica del vigneto a tendone. Tec. Agric. $2003,1-3,45-55$.

41. Ciuna, M.; Pesce, S. Il saggio di sconto variabile nella stima analitica delle colture arboree coetanee. Genio Rural. Estimo E Territ. 2003, 2, 12-22.

42. Brown, G.R.; Matysiak, G.A. Real Estate Investment: A Capital Market Approach. Ph.D. Thesis, Ekonomska Fakulteta, University of Ljubljana, Ljubljana, Slovenia, 2000.

43. Tsilimantou, E.; Delegou, E.T.; Nikitakos, I.A.; Ioannidis, C.; Moropoulou, A. GIS and BIM as integrated digital environments for modeling and monitoring of historic buildings. Appl. Sci. 2020, 10, 1078. [CrossRef] 